\title{
DIFFERENTIAL SPINAL BLOCK. II. THE REACTION OF SUDOMOTOR AND VASOMOTOR FIBERS ${ }^{1}$
}

\author{
By STANLEY J. SARNOFF AND JULIA G. ARROWOOD \\ (From the Department of Surgery and the Anesthesia Laboratory of the Harvard Medical \\ School and the Surgical Services at the Massachusetts General \\ Hospital, Boston, Massachusetts)
}

(Received for publication August 7, 1946)

In a previous communication (1), a technic was described for differentially blocking axones as they traverse the subarachnoid space. This was based upon the assumption that the smaller, unmyelinated fibers would be more susceptible to an anesthetic agent in the spinal fluid than the larger, myelinated fibers. At that time, we tested motor power and the patient's appreciation of pin-prick, touch, deep pressure, position sense, and vibratory sense. Skin temperature measurements were used as the index of vasomotor fiber block. It was found that when a 0.2 per cent solution of procaine hydrochloride was used, vasomotor fibers and pin-prick fibers were blocked while motor power and the modalities of touch, deep pressure, position sense, and vibratory sense remained unaffected.

Emmett (2) presented a series of cases in which it was rarely possible to produce a sensory and sympathetic block without a motor block by giving a small volume of procaine solution in the usual high concentrations. Unfortunately, however, the various sensory modalities were not individually examined and the observations on the results of the block were confined to the feet.

Gasser and Erlanger (3), working with cocaine, and Heinbecker, Bishop, and O'Leary (4), working with procaine, have demonstrated that the class $C$ fibers, the least myelinated of a mixed nerve, are the first to be blocked when subjected to local infiltration with the anesthetic agent. It does not necessarily follow that these fibers (in which class autonomic fibers generally fall) are blocked by a lower concentration, but it does suggest that this is so and that, therefore, these fibers could be preferentially blocked.

In this laboratory, preliminary experiments performed on the cat indicated that this was true. A powerful sympathogenic reflex, the carotid sinus

\footnotetext{
1 Presented at the Ether Day Centenary at the Massachusetts General Hospital on October 15, 1946.
}

reflex, could be abolished in the vagotomized cat by a 0.15 per cent procaine perfusion of the spinal canal [after the method of CoTui (5)], at a time when the animal maintained spontaneous respiratory activity and gave a contralateral muscular response to the electrical excitation of one femoral nerve.

The experiments of Judovich and Bates (6) are interesting in this connection. They demonstrated that varying the concentrations of ammonium chloride surrounding the saphenous nerve of the cat exerted a partially selective effect in obliterating the action potentials of the $\mathrm{A}$ and $\mathrm{C}$ type fibers. They did not clearly demonstrate that this was not a time gradient as in the work mentioned above. The selective effect of the pitcher plant distillate and ammonium salts, peripherally and intraspinally, in relieving neuralgic pain while leaving the usually tested sensations unimpaired is most stimulating; but the mechanism and fiber types involved are not clear.

This report is concerned mainly with the selective effect, on the basis of a graded concentration, on sudomotor, vasomotor and pin-prick fibers in the subarachnoid space.

\section{MATERIAL AND METHOD}

Nine sets of observations were made on seven patients of the Massachusetts General Hospital. Two of these patients were suffering from amputation stump pain, two patients were in the hospital for repair of an inguinal hernia, two for the treatment of herpes zoster, and one for diagnostic procedures relating to sciatic nerve pain. All were otherwise in a good state of health.

Six of the nine sets of observations were concerned with the reactions of the individual to a differential spinal block. The technique used was essentially that as previously described (1). It was somewhat modified in that a larger initial dose $(15 \mathrm{ml}$. rather than $10 \mathrm{ml}$. of a 0.2 per cent solution) and a higher rate of subsequently administered procaine were used. This was done because it was found that by so doing it was possible to hasten the onset of the differential block without affecting the nature of the response. 
Three sets of observations on the reaction of the patient to the usual or full spinal block were obtained. The manner in whith these blocks were performed is specified in the individual protocol. These observations were used as control studies. In two instances both the differential and undifferentiated block were performed in the same patient (R. B. and D. M.).

Iron-constantan thermocouples were placed on the plantar surface of the distal phalanx of the great toe (labelled $\mathrm{A}$ in the figures), on the medial aspect of the dorsum of the foot (B), and four inches above the internal malleolus (C). This was done on both lower extremities. A seventh thermocouple (RF) was placed on the palmar surface of the distal phalanx of the right third digit. The eighth thermocouple was placed just under the operating table so that it would register room temperature. The eight thermocouples were connected to a temperature recording device which printed in rotation every 30 seconds. By this means the temperature at each of the designated points was recorded every $4 \mathrm{~min}$ utes. ${ }^{2}$

The degree of skin resistance was used to record the order of magnitude of sweating and the changes that occurred. The instrument used was that advocated by Richter (7). The sensitivity of the indicating microammeter, or dermometer, was set at an appropriate level for each individual. This made it impossible to compare the skin resistance and the degree of sweating of one patient with that of another. However the sensitivity setting remained the same for the entire duration of the experiment in any given patient, and, therefore, qualitative changes were accurately reflected. In Figures 2 to 8 , the dermometer readings are inversely proportional to the skin resistance.

The patient was brought into a constant temperature room in which the temperature was between $17^{\circ}$ and $25^{\circ} \mathrm{C}$. In any given experiment the room temperature did not vary more than $1.6^{\circ} \mathrm{C}$. The patient's trunk was covered with a cotton sheet; the remainder of the body was bare. The patient was placed supine on the operating table which was maintained in the horizontal position at all times. Blood pressure determinations were done with the mercury manometer, adhering to the criteria of Ragan and Bordley (8). A needle was placed in the subarachnoid space in the third lumbar interspace and connected with tubing which allowed the administration of the 0.2 per cent solution of procaine. This tubing was connected to a leveling bottle which contained the anesthetic solution. A spinal fluid manometer was interpolated by means of a three-way stopcock and held by a clamp so that the zero point was on a level with the skin of the back (Figure 1). The neurologic examination used was that previously described (1). Thermal appreciation was not accurately tested and therefore the results stated do not include this modality. At the suggestion of Dr. J. C. White, tickle was tested in those two patients who were ticklish (E. H. and D. M.), by scratching the soles of their feet.

\footnotetext{
2 Brown Instrument Co., Boston, Mass.
}

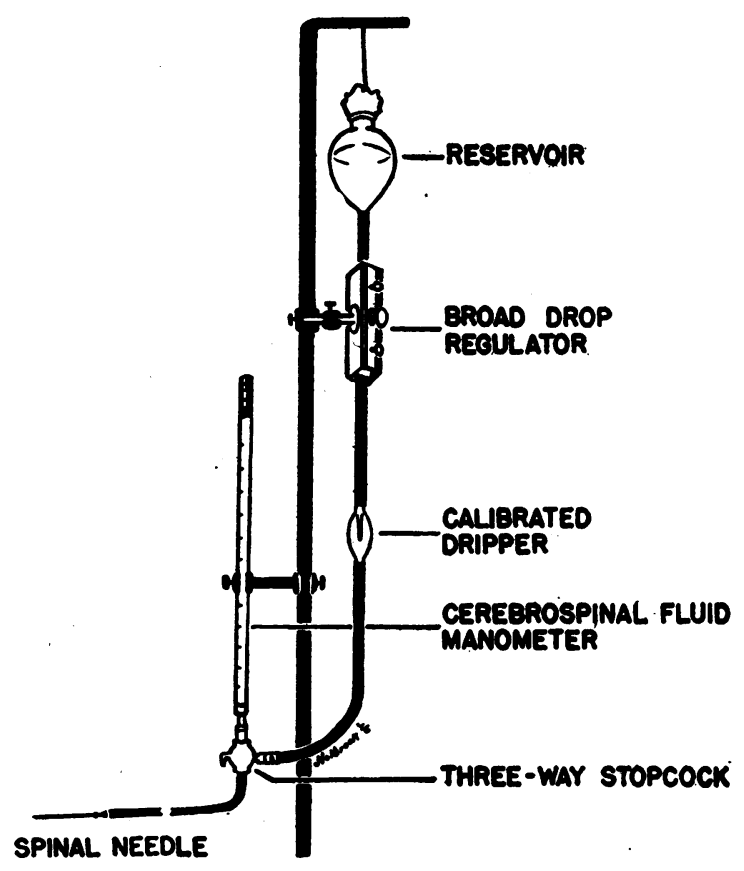

FIG. 1

The results indicate that there is a paralysis of the preganglionic sudomotor fibers which sets in at the same time as the block of the vasomotor fibers. This was true of the differential spinal block as well as of the full spinal block. The difference between the two types of block was mainly in the promptness with which the vasomotor-sudomotor block occurred. It was to be expected in addition that the full spinal block caused the loss of motor power and the other sensory modalities.

\section{Case No. 1 (R. B.): Age 55, male, right inguinal hernia.}

(Figure 2A) Satisfactory control skin resistance and skin temperature levels having been obtained, $15 \mathrm{ml}$. of a 0.2 per cent solution of procaine were administered from $11: 37$ to $11: 42$ A.M. $0.6 \mathrm{ml}$, or $1.2 \mathrm{mgm}$., per minute were then run in until 12:26 P.M. At 12:00 noon there was evidence of a beginning rise of skin temperature and skin resistance in both lower extremities. The change in the resistance and temperature of the right foot preceded that in the left foot by a few minutes, indicating the similar susceptibility of the two sets of fibers. The skin temperature of both lower extremities soon reached levels indicative of maximal vasodilatation. At 11:54 A.M., there was a spotty loss of the appreciation of pin-prick on the right. This eventually rose to the fifth thoracic segment bilaterally at 12:50 P.M. The remainder of the neurologic examination was negative. The blood pressure 


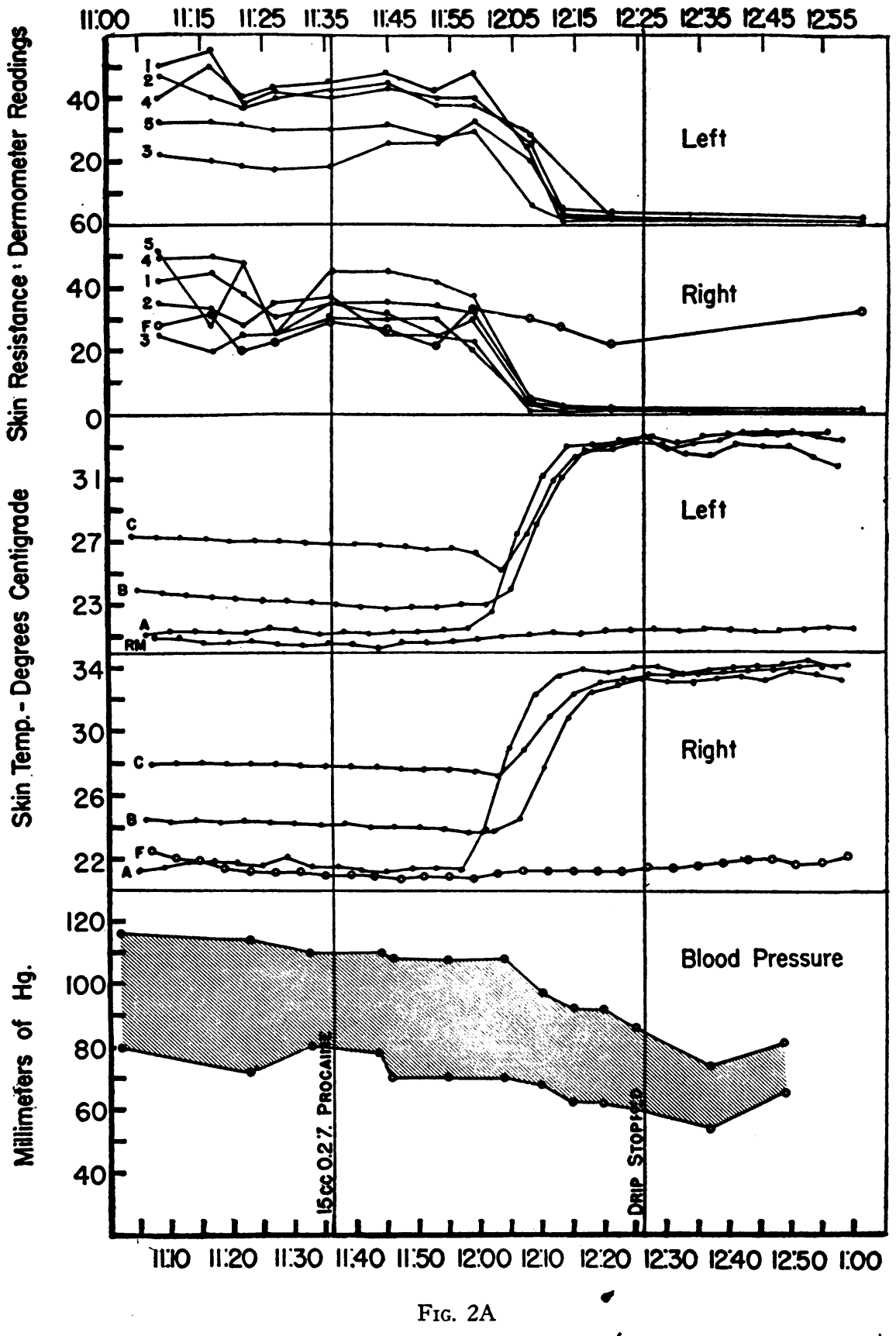

Under skin resistance, the number indicates the toe examined. The plantar surface of the distal phalanx was used in each case. $F$ indicates the readings obtained from the palmar surface of the distal phalanx of the fourth right finger. The dermometer readings are inversely proportional to the skin resistance. Under skin temperature, A represents the readings obtained from the plantar surface of the distal phalanx of the great toe, B from the medial aspect of the dorsum of the foot, and $C$ from the inner aspect of the leg four inches above the internal malleolus. F represents readings from the palmar surface of the distal phalanx of the third right finger. 


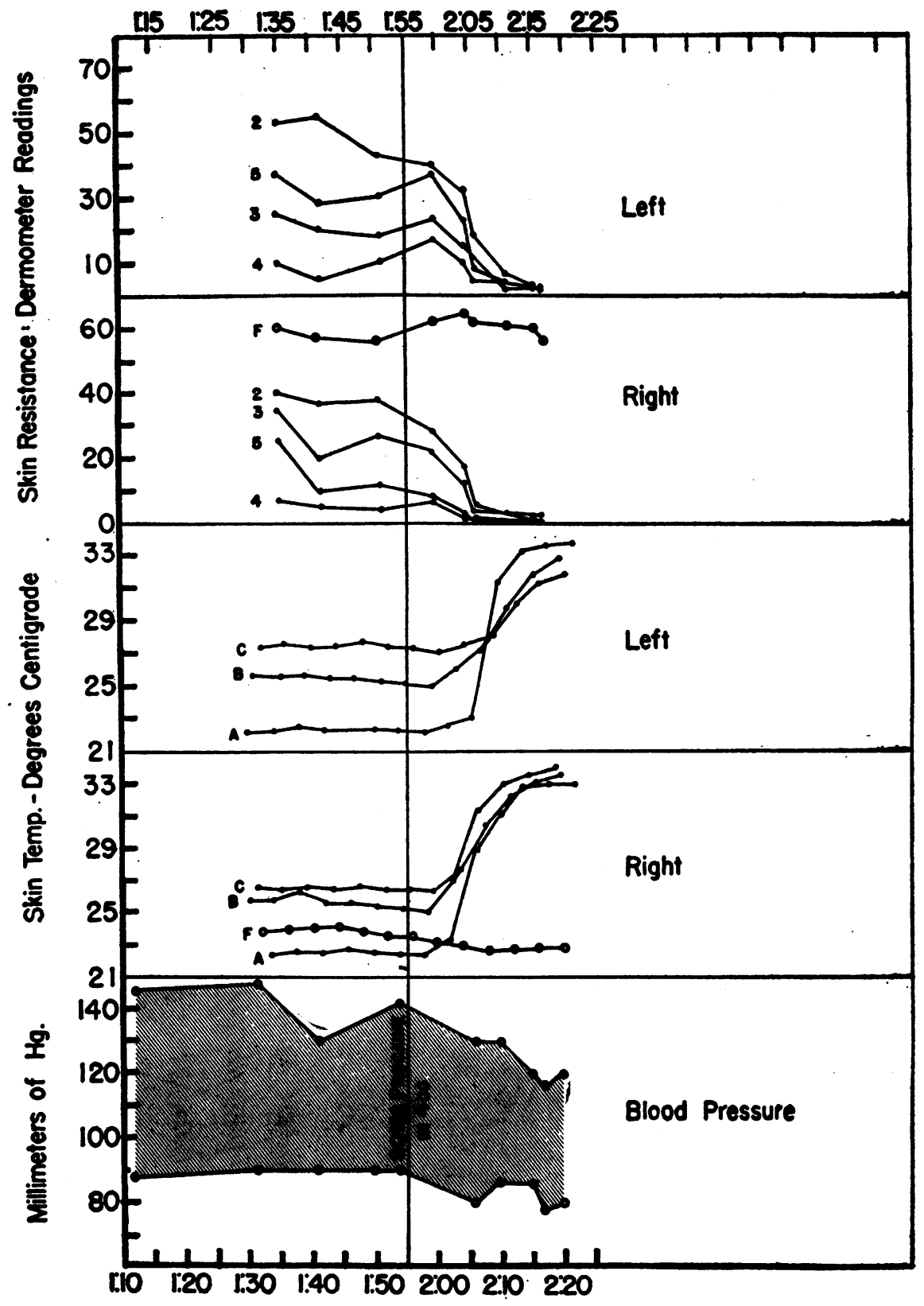

FIg. 2B

Under skin resistance, the number indicates the toe examined. The plantar surface of the distal phalanx was used in each case. $F$ indicates the readings obtained from the palmar surface of the distal phalanx of the fourth right finger. The dermometer readings are inversely proportional to the skin resistance. Under skin temperature, A represents the readings obtained from the plantar surface of the distal phalanx of the great toe, $B$ from the medial aspect of the dorsum of the foot, and $C$ from the inner aspect of the leg four inches above the internal malleolus. F represents readings from the palmar surface of the distal phalanx of the third right finger. 
fell from the control level of $110 / 80$ to a low of 74/54 at $12: 37$ P.M. A total of $90 \mathrm{mgm}$. of procaine was administered over a period of 50 minutes. At $12: 58,32 \mathrm{~min}$ utes after stopping the drip, a full sudomotor and vasomotor block was still present.

Ten days later, a full spinal block was administered to the same patient (Figure 2B). After control levels were established, $80 \mathrm{mgm}$. of procaine hydrochloride in $4 \mathrm{ml}$. of cerebrospinal fluid were injected into the subarachnoid space in the third lumbar interspace. This was followed by the administration of $0.3 \mathrm{ml}$. per minute of a 0.5 per cent solution of the same agent. A rise in skin temperature and skin resistance in the feet was in evidence within 5 minutes of the injection. The slope of the curve was slightly steeper than when the differential block was administered; but in other respects they were similar. The loss of motor power and sensation was that usually seen with full spinal blocks. The fall in systolic arterial pressure was not so great after the full spinal block as after the differential block (in terms either of absolute or per- centile change) despite the fact that muscular paralysis accompanied the former and not the latter.

Case No. 2 (D. M.): Age 38, male. Left mid-thigh amputation stump pain.

(Figure 3A) Control levels having been obtained, 15 ml. of a 0.2 per cent solution of procaine hydrochloride were run in between $3: 52$ and 3:55 P.M. From then until 4:50 P.M., $1.6 \mathrm{mgm}$. per minute of the same solution were administered. The skin temperature and skin resistance of the right foot began to rise simultaneously between $4: 10$ and $4: 15$ P.M. The skin temperature reached levels indicative of maximal vasodilatation. At 4:10 P.M., there was a just discernible, spotty loss of appreciation of pin-prick on the right anterior thigh. Complete loss of pin-prick sensation eventually rose to the first thoracic segment at $4: 51$ P.M. At $4: 43$ P.M., the appreciation of tickle was unchanged. The remainder of the neurologic examination was negative. The blood pressure remained

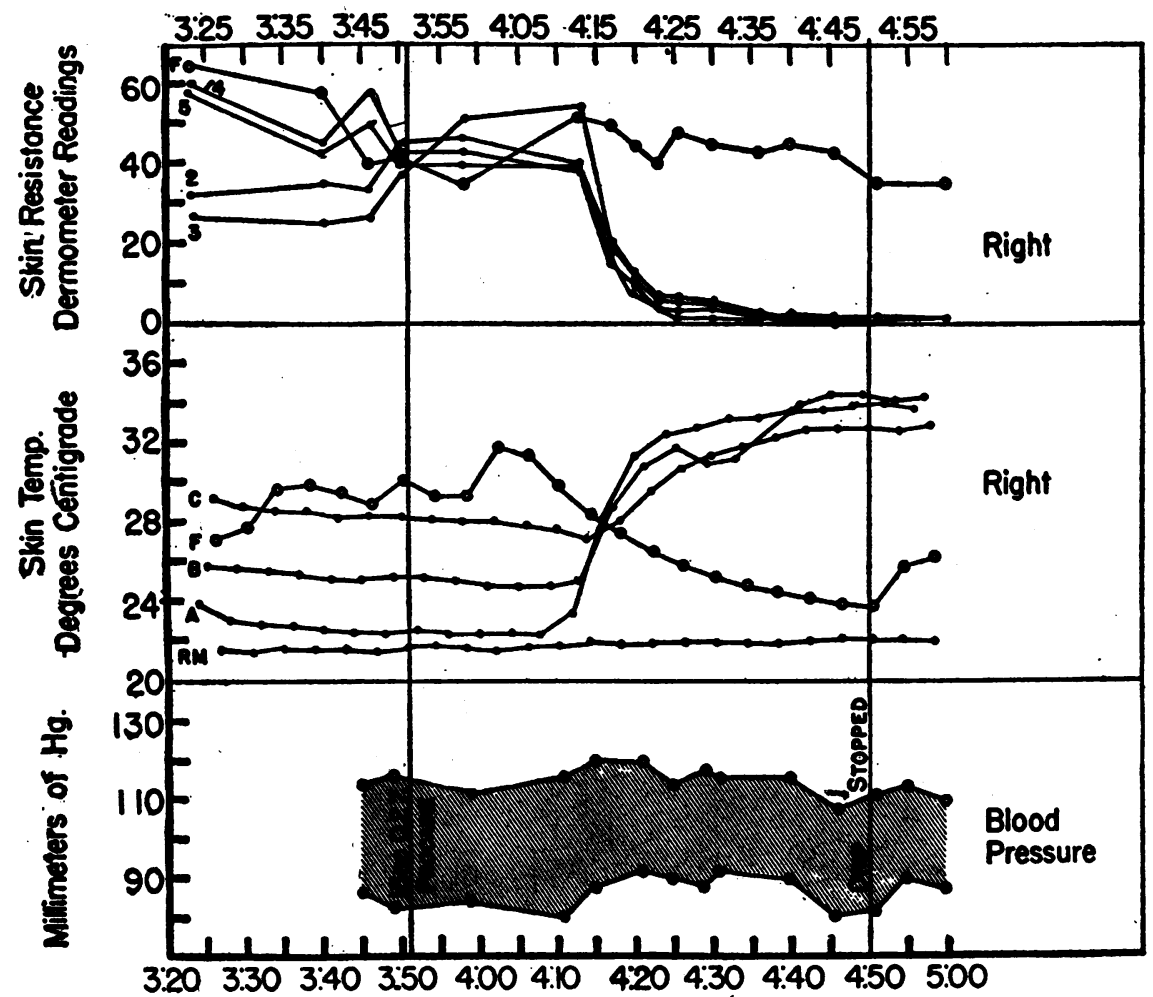

Fig. 3A

Under skin resistance, the number indicates the toe examined. The plantar surface of the distal phalanx was used in each case. $F$ indicates the readings obtained from the palmar surface of the distal phalanx of the fourth right finger. The dermometer readings are inversely proportional to the skin resistance. Under skin temperature, A represents the readings obtained from the plantar surface of the distal phalanx of the great toe, $B$ from the medial aspect of the dorsum of the foot, and $C$ from the inner aspect of the leg four inches above the internal malleolus. F represents readings from the palmar surface of the distal phalanx of the third right finger. 
essentially unchanged. A total of $116 \mathrm{mgm}$. of procaine was administered over a period of 60 minutes.

Two days later, a full spinal block was administered to the same patient (Figure 3B). After obtaining control levels, $150 \mathrm{mgm}$. of procaine in $5 \mathrm{ml}$. of normal saline were injected into the subarachnoid space at the third lumbar interspace. No additional injections were made. This was followed almost immediately by a rise in skin temperature and skin resistance. The curves obtained closely resembled the curves obtained with the differential spinal block in the same patient, with the exception that, with the full block, the skin temperatures did not rise so high during the period of observation. The blood pressure did not change appreciably; but, if anything, the average post-injection level was slightly higher than the average control level.
Case No. 3 (A. D.): Age 68, female. Post-herpetic neuralgia.

(Figure 4) Satisfactory control levels of skin temperature and skin resistance having been obtained, $15 \mathrm{ml}$. of a $\mathbf{0 . 2}$ per cent solution of procaine hydrochloride were run in between $4: 35$ and $4: 39$ P.M. From then until $4: 58$, $1.2 \mathrm{mgm}$. per minute were administered and from 4:58 to 5 :22 P.M., $2.0 \mathrm{mgm}$. per minute of the same solution were given. The changes in skin temperature and skin resistance in the feet were manifest in the right foot slightly before the left, indicating, as in Case R. B., the similar susceptibility of the two types of fibers to the given concentration of procaine. It is likely that the presence of hypertensive and arteriosclerotic disease limited the height to which the skin temperature rose in this individual. The contour of the curve, however, indicates that the

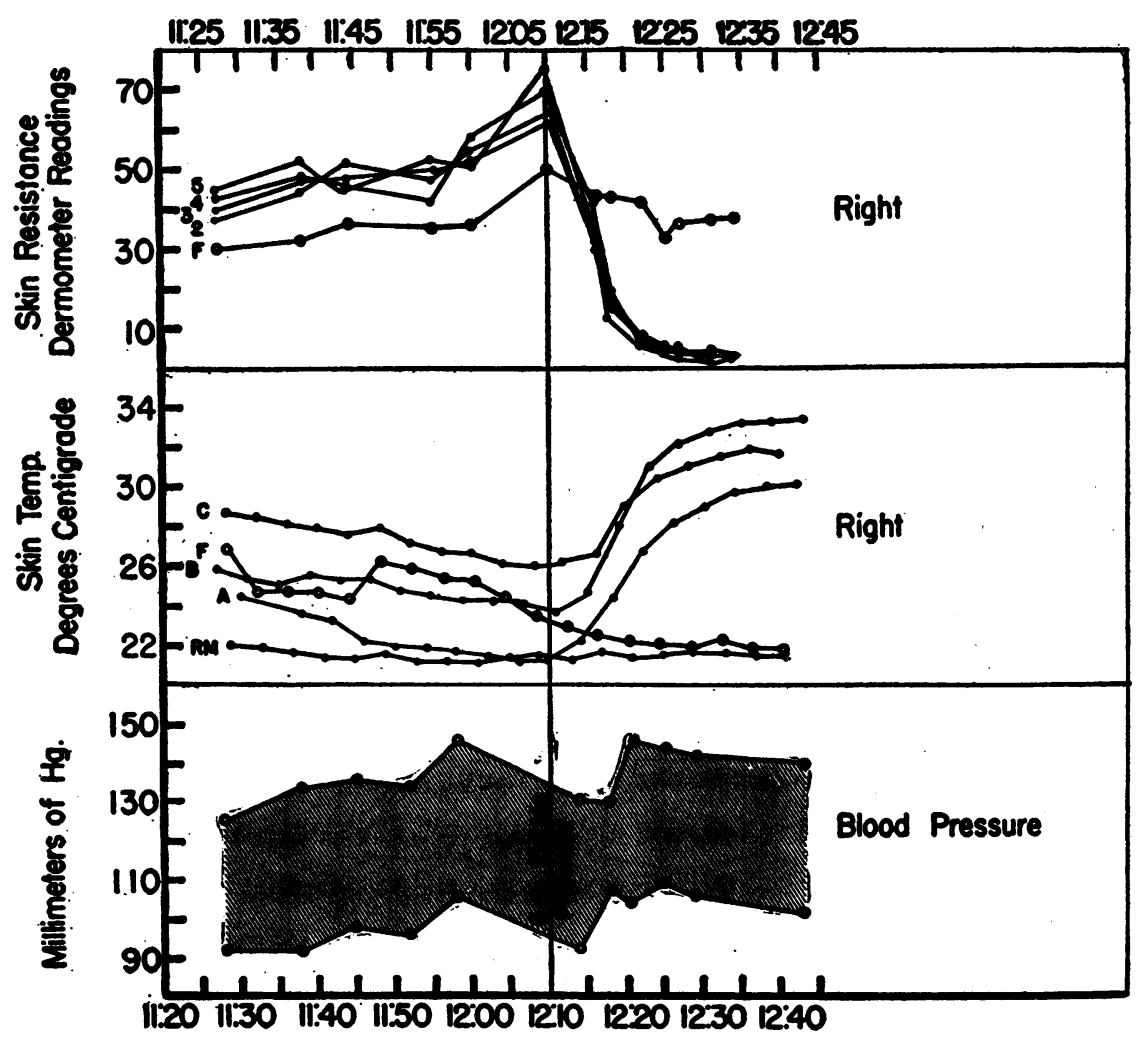

Fig. 3B

Under skin resistance, the number indicates the toe examined. The plantar surface of the distal phalanx was used in each case. $F$ indicates the readings obtained from the palmar surface of the distal phalanx of the fourth right finger. The dermometer readings are inversely proportional to the skin resistance. Under skin temperature, A represents the readings obtained from the plantar surface of the distal phalanx of the great toe, $B$ from the medial aspect of the dorsum of the foot, and $C$ from the inner aspect of the leg four inches above the internal malleolus. F represents readings from the palmar surface of the distal phalanx of the third right finger. 


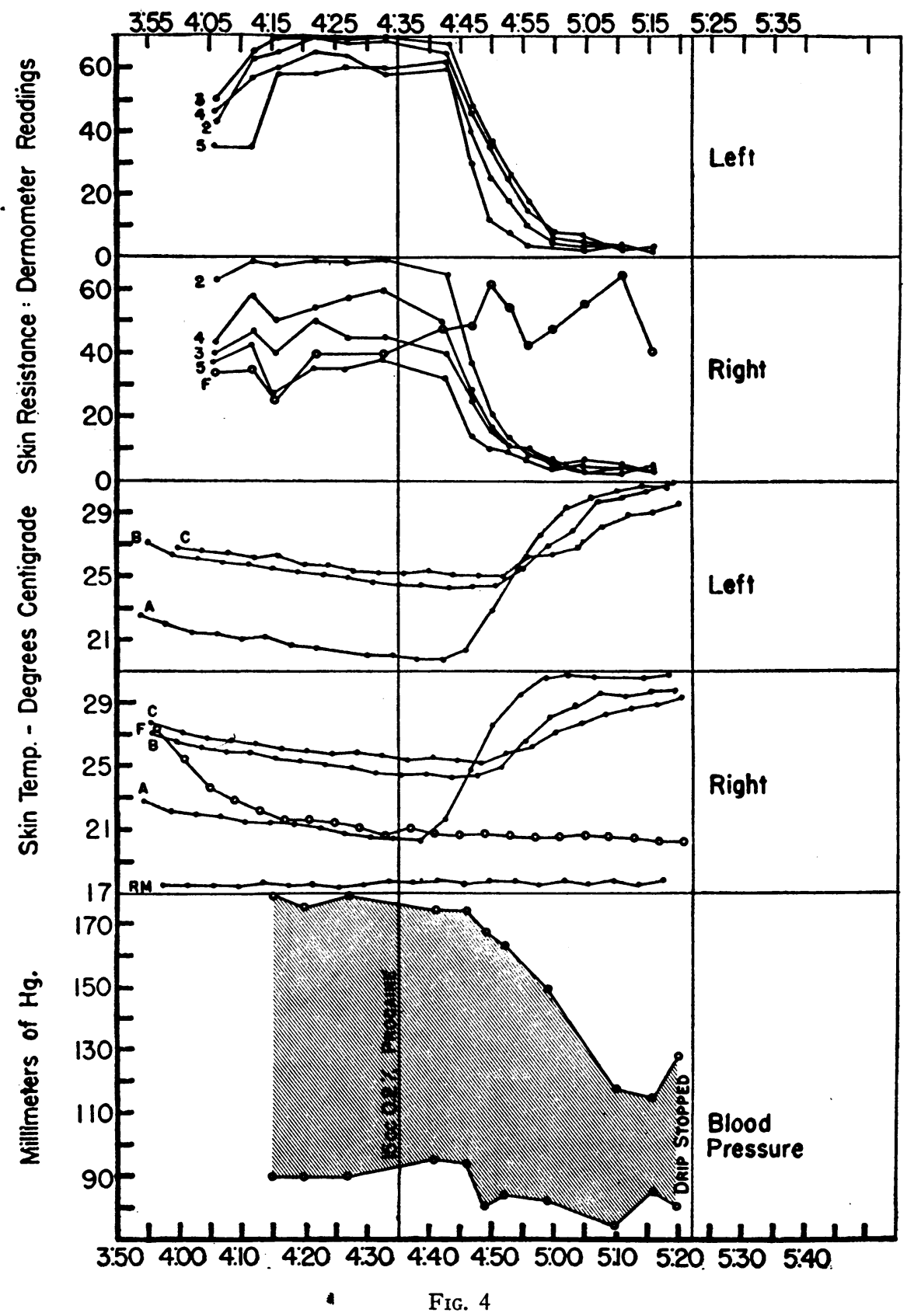

Under skin resistance, the number indicates the toe examined. The plantar surface of the disţal phalanx was used in each case. $F$ indicates the readings obtained from the palmar surface of the distal phalanx of the fourth right finger. The dermometer readings are inversely proportional to the skin resistance. Under skin temperature, A represents the readings obtained from the plantar surface of the distal phalanx of the great toe, $B$ from the medial aspect of the dorsum of the foot, and $C$ from the inner aspect of the leg four inches above the internal malleolus. F represents readings from the palmar surface of the distal phalanx of the third right finger. 


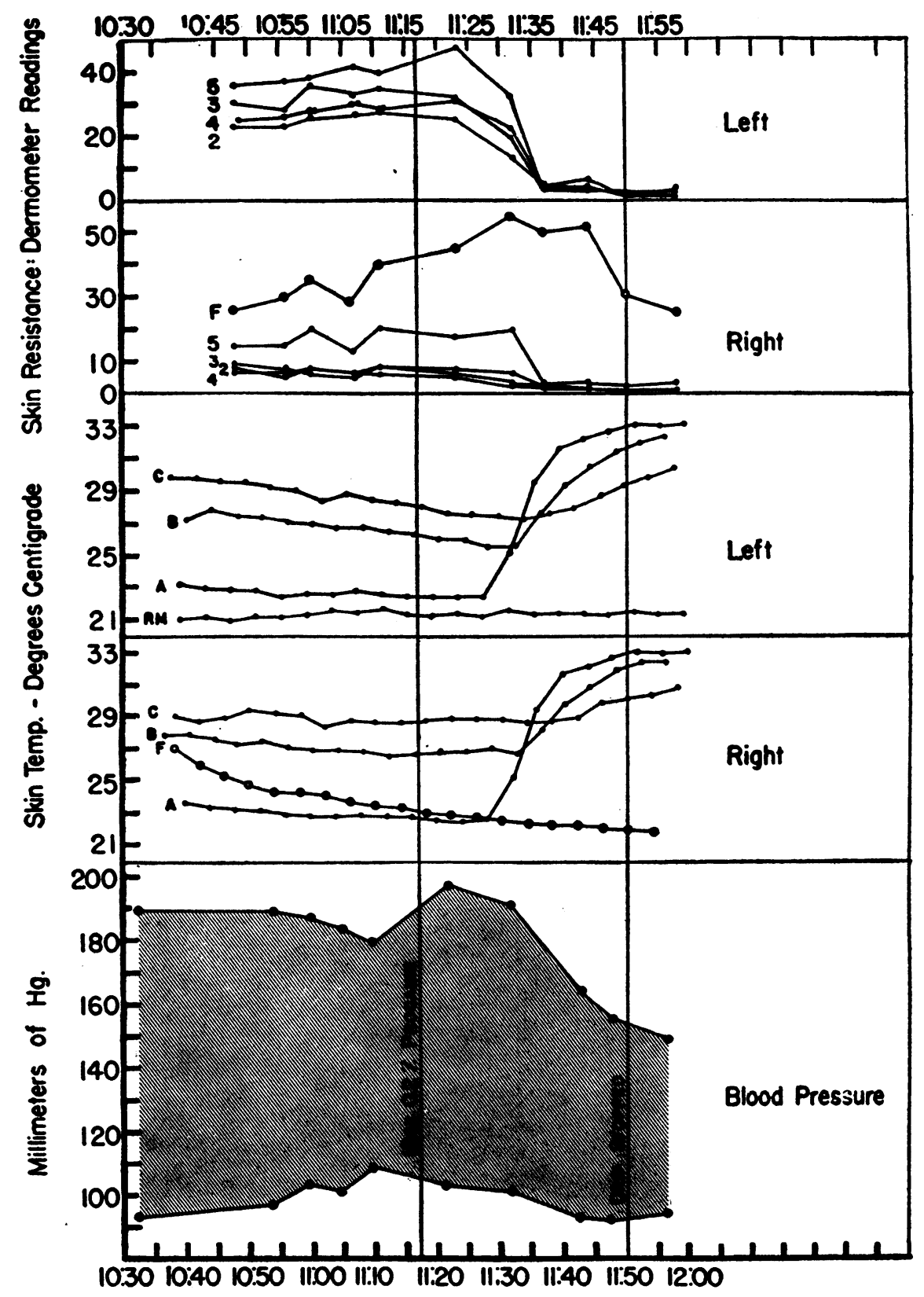

Fig. 5

Under skin resistance, the number indicates the toe examined. The plantar surface of the distal phalanx was used in each case. $F$ indicates the readings obtained from the palmar surface of the distal phalanx of the fourth right finger. The dermometer readings are inversely proportional to the skin resistance. Under skin temperature, A represents the readings obtained from the plantar surface of the distal phalanx of the great toe, B from the medial aspect of the dorsum of the foot, and $C$ from the inner aspect of the leg four inches above the internal malleolus. F represents readings from the palmar surface of the distal phalanx of the third right finger. 


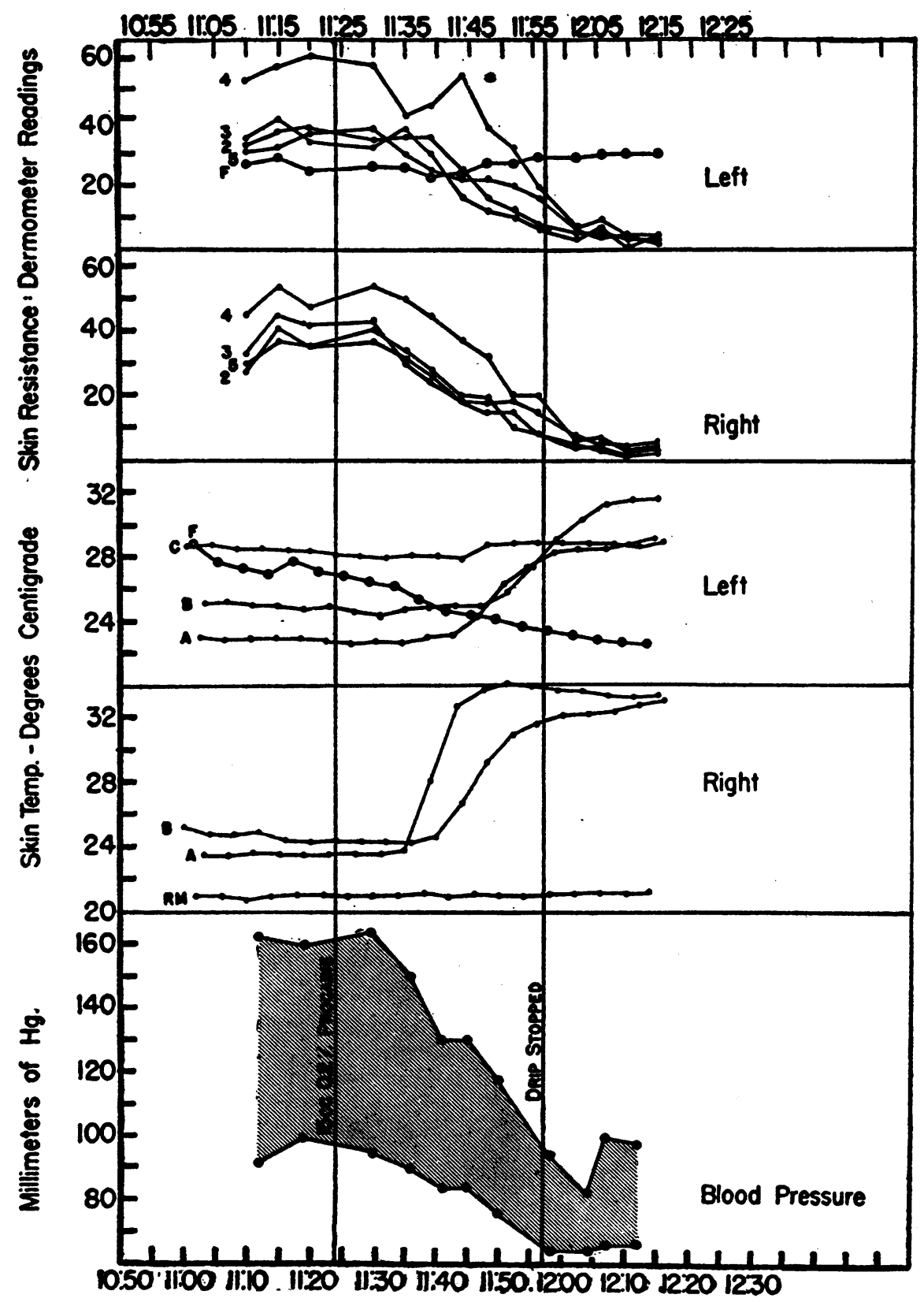

FIg. 6

Under skin resistance, the number indicates the toe examined. The plantar surface of the distal phalanx was used in each case. $F$ indicates the readings obtained from the palmar surface of the distal phalanx of the fourth right finger. The dermometer readings are inversely proportional to the skin resistance. Under skin temperature, A represents the readings obtained from the plantar surface of the distal phalanx of the great toe, B from the medial aspect of the dorsum of the foot, and $C$ from the inner aspect of the leg four inches above the internal malleolus. F represents readings from the palmar surface of the distal phalanx of the third right finger. 
greatest vasodilatation possible in this individual with the use of a chemical block was achieved. At $4: 40$, there was a patchy loss of the appreciation of pin-prick on the dorsum of both feet. Complete loss of pin-prick sensation eventually rose to the fourth thoracic segment at $5: 01$ P.M. The remainder of the neurologic examination was negative. The systolic arterial pressure fell from the control level of 178 to $115 \mathrm{~mm}$. $\mathrm{Hg}$. A total of $101 \mathrm{mgm}$. of procaine was administered over a period of 47 minutes.

Case No. 4 (E. H.): Age 72, female. Amputation stump and phantom pain.

(Figure 5) Previous local nerve section in an attempt to ameliorate the pain in the absent right fifth toe, resulted in high levels of skin resistance in that foot in the control period. The vibratory sense was severely impaired during the control period. After obtaining satisfactory control levels, $15 \mathrm{ml}$. of a 0.2 per cent solution of procaine were administered between $11: 17$ and $11: 20$ A.M. From then until 11:50 A.M., $1.2 \mathrm{mgm}$. per minute of the 0.2 per cent solution was administered. Between 11:25 and $11: 30$ A.M. there was evidence of an increase in the skin temperature and skin resistance of the feet. The skin temperature rose to levels indicative of maximal vasodilatation. At 11:27 A.M. there was a beginning loss of appreciation of pin-prick. This eventually rose to the eighth thoracic segment. The remainder of the neurologic examination, including tickle, remained unchanged. The systolic arterial pressure fell from a control level of $185 \mathrm{~mm}$. to $150 \mathrm{~mm}$. Hg. A total of $66 \mathrm{mgm}$. of procaine was administered over a period of 33 minutes.

Case No. 5 (C. P.): Age 42, male. Differential diagnosis between right sciatic nerve pain and psychoneurosis.

(Figure 6) Satisfactory control levels having been obtained, $15 \mathrm{ml}$. of a 0.2 per cent solution of procaine were administered from $11: 24$ to $11: 27$ A.M. From then until 11:57 A.M., $1.6 \mathrm{mgm}$. per minute of the 'same solution were given. At $11: 35$ A.M. there was evidence of vasomotor and sudomotor block in both lower extremities. The rise in skin temperature of the right foot indicated maximal vasodilatation while that on the left resembled the curve seen with moderate peripheral vascular disease of the occlusive type. There was no dorsalis pedis pulsation to be felt on that side. The slope of the increase in skin resistance was gentler than that seen in the preceding patients. At $11: 43$ A.M., there was a loss of appreciation to pin-prick at the level of the third lumbar segment and this rose to the second lumbar segment at $11: 46$. The systolic arterial pressure fell from the control level of 161 to $82 \mathrm{~mm}$. $\mathrm{Hg}$. The remainder of the neurological examination remained unchanged. A total of $75 \mathrm{mgm}$. of procaine was administered over a period of 33 minutes.
Case No. 6 (J. B.): Age 42, male. Question of postherpetic neuralgia.

(Figure 7) At the onset of this period of observation, the patient's lower extremities were quite dry and the skin resistance correspondingly high, despite the slightly higher room temperature than that generally used. A higher room temperature could not be used because the skin temperature was already at a level where further elevation would compromise the end-point for vasomotor block. Thus the sensitivity setting of the dermometer had to be set quite high. After obtaining control levels, $15 \mathrm{ml}$. of a 0.2 per cent solution of procaine were administered between $2: 56$ and $3: 01$ P.M. From then until $3: 48,1.6 \mathrm{mgm}$. per minute of the same solution were given. At 3:04 .P.M., there was evidence of a rise in skin temperature and skin resistance in both lower extremities. The skin temperature rose to levels indicative of maximal vasodilatation. The rise in skin resistance was less striking and less regular than in any of the previous patients. It was thought that further drying off of a foot that is already quite dry might yield such a curve. In any case the evidence for a sudomotor block is not so clear as in the other cases observed. At 3:13 P.M., there was a loss of the appreciation of pin-prick to the level of the tenth thoracic segment. This eventually rose to the second thoracic segment at 3:38 P.M. The rest of the neurological examination remained unchanged. A total of $105 \mathrm{mgm}$. of procaine was administered over a period of 52 minutes.

\section{Case No. 7 (J.M.): Age 21, male. Right inguinal hernia.}

(Figure 8) A full spinal block was performed in this patient. He was quite apprehensive, since this procedure was performed immediately prior to operation. All premedication had been omitted for the purposes of this experiment. The room temperature was the highest used for any experiment in this series, and the patient's extremities were all obviously moist. The sensitivity setting of the dermometer thus had to be made quite low in order to bring the needle deflections within the readable scale. At 11:11 A.M., during the control period, the particular surgeon whom the patient knew was to perform the operation, came into the room and announced that they were ready to start. At $11: 13$ there was a sharp fall in the skin resistance. At $11: 17,100 \mathrm{mgm}$. of procaine in $4 \mathrm{ml}$. of cerebrospinal fluid were injected into the subarachnoid space at the third lumbar interspace. This was followed by the administration of $0.4 \mathrm{ml}$. per minute of a 0.5 per cent solution of the same agent. At $11: 21$ there was evidence of vasomotor and sudomotor block. The skin temperature of the feet rose to levels indicative of maximal vasodilatation, and the skin resistance rose sharply. The patient was not followed closely thereafter, but inasmuch as the operative procedure was completed without discomfort to the patient and with adequate muscular relaxation, it is likely that the full block was that as usually seen. At the end of the period of observation $(11: 32)$ the patient's blood pressure had risen about $5 \mathrm{~mm}$. $\mathrm{Hg}$. 


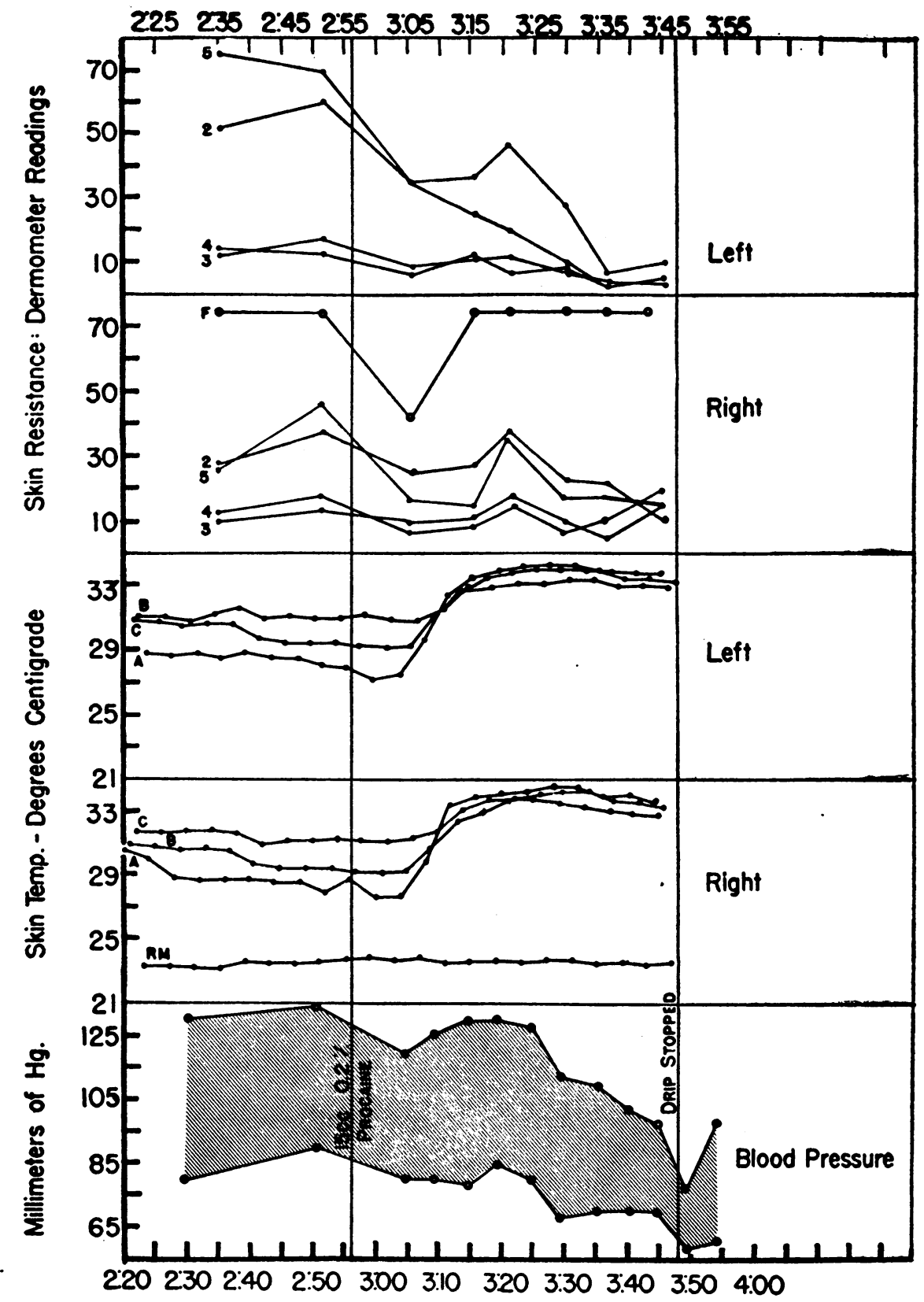

FIG. 7

Under skin resistance, the number indicates the toe examined. The plantar surface of the distal phalanx was used in each case. $F$ indicates the readings obtained from the palmar surface of the distal phalanx of the fourth right finger. The dermometer readings are inversely proportional to the skin resistance. Under skin temperature, A represents the readings obtained from the plantar surface of the distal phalanx of the great toe, B from the medial aspect of the dorsum of the foot, and $C$ from the inner aspect of the leg four inches above the internal malleolus. F represents readings from the palmar surface of the distal phalanx of the third right finger. 


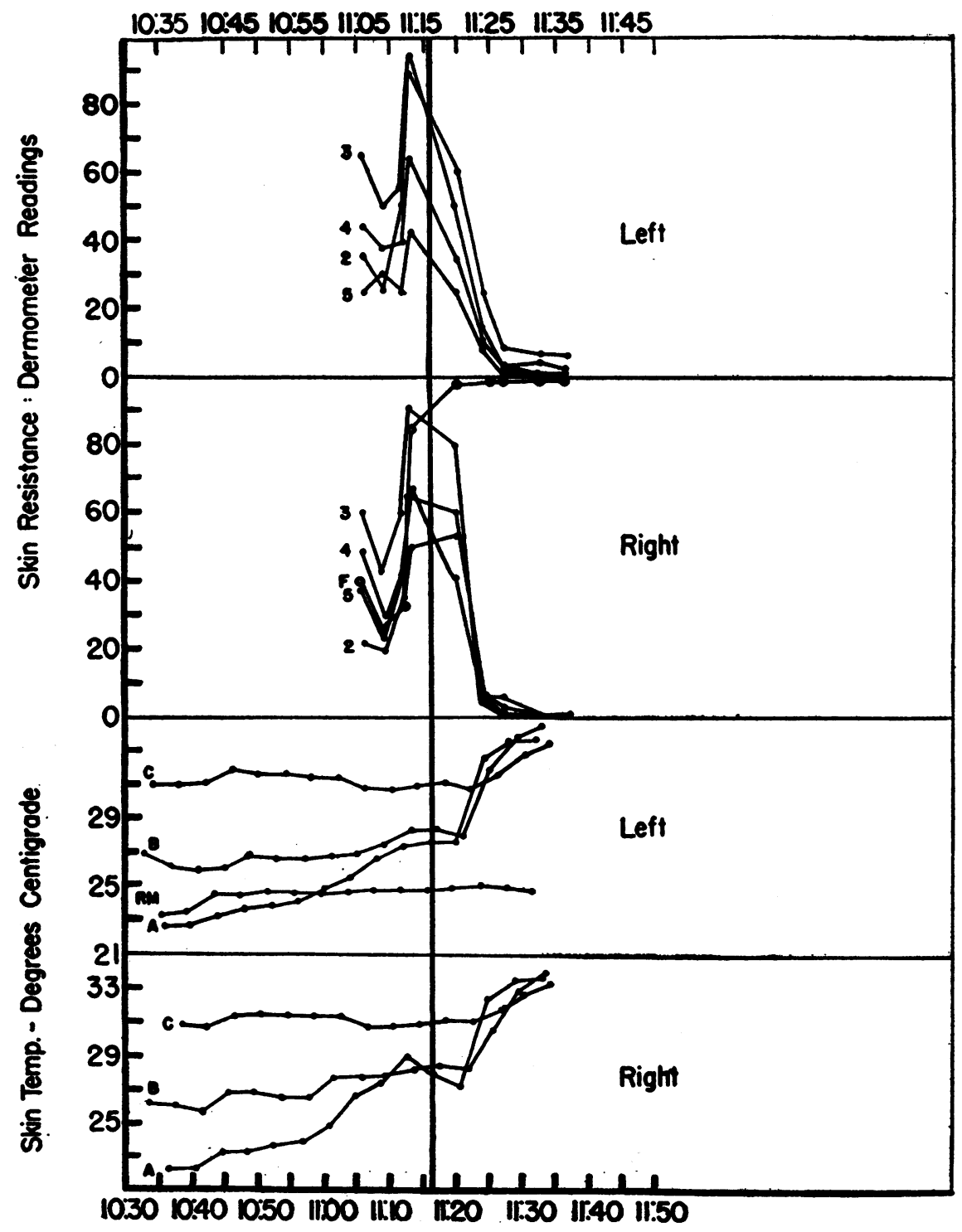

FIG. 8

Under skin resistance, the number indicates the toe examined. The plantar surface of the distal phalanx was used in each case. $F$ indicates the readings obtained from the palmar surface of the distal phalanx of the fourth right finger. The dermometer readings are inversely proportional to the skin resistance. Under skin temperature, A represents the readings obtained from the plantar surface of the distal phalanx of the great toe, B from the medial aspect of the dorsum of the foot, and $\mathrm{C}$ from the inner aspect of the leg four inches above the internal malleolus. F represents readings from the palmar surface of the distal phalanx of the third right finger.

\section{DISCUSSION}

The data just presented indicate that preganglionic sudomotor fibers are blocked by the concentration of procaine which results from the dilution of the 0.2 per cent solution introduced in the amounts stated above. They are apparently blocked simultaneously with the preganglionic vasomotor fibers and either preceded or followed by a block of fibers concerned with the appreciation of pin-prick. This concentration of the 
agent leaves unaffected the fibers, mediating position sense, vibratory sense, touch, deep pressure, and motor power, insofar as this is reflected by the neurological examination used. The data presented here may be considered confirmatory of the preliminary report recently published (1).

In the two patients of this series in whom tickle was tested, the sensation was unimpaired at a time when there was a complete loss of the appreciation of pin-prick. Three subsequent patients have been studied in regard to this modality. In one of these there was no impairment, in one there was partial impairment, and in one there was complete loss. It would seem therefore, that although this modality is distinct from that of appreciation of pin-prick, the fiber that subserves it is more nearly like that of the pain fiber in size and myelination than are the fibers subserving motor power, position sense, touch, and vibratory sense.

The degree of myelination and fiber size of the various components of spinal nerves have been reviewed by Ransom (13). He states that efferents to skeletal muscles are myelinated fibers, which are, for the most part, of large caliber. Touch is mediated by larger myelinated fibers, while pain is mediated by the fine myelinated or unmyelinated fibers. It is also stated that proprioceptive fibers are myelinated. Sympathetic fibers (efferent) are all finely myelinated (14).

If the assumption is made that the centrally directed axones from the spinal ganglia are similar to those of the peripheral axones, the data herewith presented would seem to be in accord with accepted morphologic data. One important exception has been noted (11) in that it has been found that the knee kicks and ankle jerks disappear at a time when position sense is unimpaired. This would make it seem that the stretch afferents differ from other proprioceptive fibers in that they are relatively small unmyelinated fibers. It should be emphasized that these data are significant only for the subarachnoid portion of the spinal nerves.

It was previously stated that a differential block, without motor loss, induced a degree of hypotension similar to that seen in full or undifferentiated spinal block (1). This was interpreted as meaning that muscular paralysis and the venular stasis that supposedly follows it contrib- ute little to the hypotension of spinal anesthesia in the horizontal position. With one exception, the falls in arterial pressure seen in the patients of this series subjected to a differential block were of the same order of magnitude as those seen after full spinal block. This one exception (Case D. M.) failed to have a fall with a full spinal block as well, and indeed, had a slight rise. The nature of this patient's response is not clearly understood.

The technic of differential spinal block is not to be construed as an anesthetic procedure. Rather, it has proved useful in the investigation of problems concerned with the peripheral nervous system such as amputation stump and phantom limb pain (9). The technic has yielded interesting information in patients with intestinal dyskinesia and colonic atony. Since somatic motor paralysis is not present, one may introduce amounts of procaine solution high enough in the spinal canal to be sure of blocking all visceral efferents to the intestinal tract (10).

In a recently concluded study, the knee kick, ankle jerk and abdominal reflexes were examined in twelve patients under the influence of a differential spinal block as described above. It had previously been thought that position sense and the stretch afferents were, by and large, subserved by the same group of proprioceptive afferent fibers. That this is not the case is indicated by the fact that these reflexes were abolished in every case while position sense remained unchanged (11).

It had previously been demonstrated that the undifferentiated type of spinal block confers benefit upon the patient suffering from pulmonary edema due to cardiac decompensation (12). It was thought that the arteriolar dilatation would diminish the resistance against which the left ventricle would have to work, and also that the pooling of blood in the periphery would significantly diminish the return flow to the right heart. The drawback to the procedure as it was practised at that time is that a partial intercostal paralysis accompanied the peripheral pooling effect. This was felt to be hazardous in the dyspneic patient in need of full respiratory excursions. The technic of differential spinal block, however, allows one to induce the peripheral vasodilatation without the intercostal paralysis. Two patients have been so 
treated and responded with a convincing clinical improvement. This was temporary in one. In one of these patients arterial and venous oxygen determinations were performed and clearly confirmed the clinical impression.

Previous data (1) demonstrated that it was possible to produce a chemical sympathectomy of the upper as well as the lower extremity by means of a differential spinal block. From the above data it can be seen that the degree of vasodilatation induced with the differential spinal block is equivalent to that induced with a full spinal block. It should therefore be useful as a prognostic technic in patients with peripheral vascular disease.

At the present time a differential spinal block is performed almost routinely preoperatively in hypertensive patients. Since the technic is essentially a reversible sympathectomy, an attempt will be made to ascertain whether or not the fall in blood pressure induced by the block will correspond to that accomplished by sympathectomy.

An interesting but as yet unexplained side effect noticed in about one-third of patients is the observation that they become distinctly somnolent at a time when procaine is high in the spinal canal.

If the basic assumption is correct, and we believe it to be so, that relative susceptibility to graded concentrations of the anesthetic agent depends upon fiber size and degree of myelination, then the above data are indicative of the nature of the preganglionic sudomotor fibers. Such a conclusion, based upon this type of clinical evidence, is in agreement with the early observations of Gaskell (14) who demonstrated that preganglionic sympathetic efferents were morphologically indistinguishable from one another.

\section{SUMMARY}

1. Preganglionic sudomotor fibers in the subarachnoid space are blocked by the introduction of appropriate amounts of 0.2 per cent procaine hydrochloride.

2. The onset of the sudomotor block is simultaneous with the paralysis of the preganglionic peripheral vasoconstrictor fibers. This is either preceded or followed by a block of fibers concerned with the appreciation of pin-prick.

3 . The preganglionic sudomotor fibers are susceptible to a concentration of anesthetic agent which leaves motor, touch, deep pressure, vibratory sense, and position sense fibers intact.

4. Fibers subserving the tickle sensation are generally unaffected and are distinct from those mediating pain.

5. The rôle of muscular paralysis in the genesis of the hypotension seen with spinal anesthesia must be very limited.

\section{BIBLIOGRAPHY}

1. Sarnoff, S. J., and Arrowood, J. G., Differential spinal block. A preliminary report. Surgery, 1946, 20, 150.

2. Emmett, J. L., Subarachnoid injections of procaine hydrochloride; quantitative effects of clinical doses on sensory, sympathetic and motor nerves. J. A. M. A., 1934, 102, 425.

3. Gasser, H. S., and Erlanger, J., Role of fiber size in establishment of nerve block by pressure or cocaine. Am. J. Physiol., 1929, 88, 581.

4. Heinbecker, P., Bishop, G. H., and O'Leary, J., Analysis of sensation in terms of nerve impulse. Arch. Neurol. and Psychiat., 1934, 31, 34.

5. Co Tui, Burstein, C. L., and Ruggiero, W. F., Total spinal block; a preliminary report. Anesthesiology, 1940, 1, 280.

6. Judovich, B., and Bates, W., Segmental Neuralgia in Painful Syndromes. F. A. Davis Company, Phila., 1944.

7. Richter, C. P., and Otenasek, F. J., Thoracolumbar sympathectomies examined with the skin resistance method. J. Neurosurg., 1946, 3, 120.

8. Ragan, C., and Bordley, J., III, Accuracy of clinical measurements of arterial blood pressure, with note on auscultatory gap. Bull. Johns Hopkins Hosp., 1941, 69, 504.

9. Arrowood, J. G., and Sarnoff, S. J., Differential spinal block. $\mathrm{V}$. Investigation of the peripheral nerve fibers subserving amputation stump and phantom limb pain. (Manuscript in preparation.)

10. Sarnoff, S. J., Arrowood, J. G., and Chapman, W. G., Differential spinal block. IV. Investigation of intestinal dyskinesia, colonic atony and visceral afferents. (Manuscript in preparation.)

11. Sarnoff, S. J., and Arrowood, J. G., Differential spinal block. III. The abolition of cutaneous and stretch reflexes in the presence of unimpaired position sense. J. Neurophysiol. (In press.)

12. Sarnoff, S. J., and Farr, H. W., Spinal anesthesia in the therapy of pulmonary edema. A preliminary report. Anesthesiology, 1944, 5, 69.

13. Ranson, S. W., The Anatomy of the Nervous System. W. B. Saunders \& Co., Phila. 7th edition, 1943. Chapter 5.

14. Gaskell, W. H., On the structure, distribution, and function of the nerves which innervate the visceral and vascular systems. J. Physiol., 1886, 7, 1. 